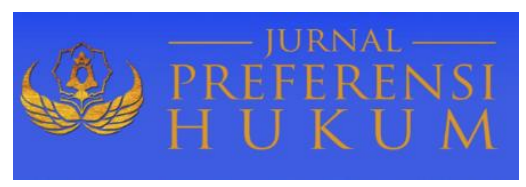

Jurnal Preferensi Hukum | ISSN: XXXX | E-ISSN: XXXX

Vol. 1 No. 1 - Juli 2020 hal. 14-20| Available online at https://www.ejournal.warmadewa.ac.id/index.php/juprehum

\title{
PERANAN RESERSE KRIMINAL DALAM MENGUNGKAP TINDAK PIDANA PENCURIAN KENDARAAN BERMOTOR DI WILAYAH HUKUM POLSEK UBUD
}

\author{
I Gusti Ngurah Arya Brahmantara, Anak Agung Sagung Laksmi Dewi, Ni Made Sukaryati Karma \\ Fakultas Hukum Universitas Warmadewa, Denpasar - Bali, Indonesia
}

\begin{abstract}
Abstrak
Maraknya tindakan kejahatan yang terjadi di hampir seluruh dunia telah menjadi pusat perhatian bukan saja penegak keamanan dan masyarakat tetapi juga peneliti untuk berusaha mengungkap motif serta strategi-strategi pencegahan dan penanganannya. Seperti halnya di Indonesia, khususnya di wilayah Bali - daerah pusat utama kegiatan pariwisata Indonesia - kejahatan dalam berbagai wujud kerap sekali terjadi. Kajian ini mengungkap upaya polisi dalam mengungkap kasus pelaku tindak kejahatan pencurian kendaraan bermotor yang terjadi di Jalan Raya Andong, Desa Petulu, Ubud - Bali, serta faktor penghambat yang dihadapi. Untuk mencapai tujuan ini, kajiaan menggunakan desain penelitian kualitatif dan metode penelitian hukum empiris dan yuridis sosiologis. Hasil kajian menunjukkan bahwa terdapat dua tindakan polisi yang telah dilakukan. Pertama, tindakan pre-emitif yang terealisasi melalui bimbingan masyarakat melalui BHABINKAMTIBMAS. Kedua ialah tindakan preventif melalui kegiatan patroli-patroli dan pemeriksaan penertiban kelengkapan kendaraan bermotor. Yang terakhir ialah tindakan represif, yang mana, polisi melakukan tindakan sesuai laporan polisi model (A) dan (B). Dalam upaya pengungkapan tindakan ini, beberapa kendala dihadapi, antara lain: faktor internal yakni jumlah penyidik yangbelum memadai, sarana dan fasilitas seperti alat pemindai sidik jari yang juag belum memadai dan anggaran yang terbatas; dan faktor eksternal yang meliputi CCTV yang kurang memadai, minimnya jumlah saksi, kelalaian pemilik kendaraan, pelaku dan barang curian sudah berada di luar wilayah Bali. Kurangnya saksi, terutama tetapi tidak terbatas pada residivis, dalam upaya mengungkap kejahatan menyiratkan bahwa sarana serta fasilitas yang canggih dan memadai mempunyai fungsi, manfaat, dan sifat mendesak untuk dilengkapi demi mewujudkan keamanan dan kedamaian bangsa. Terkait hal, ini Reserse Kriminal mempunyai peranan krusial yang perlu diaktualisasikan segera.
\end{abstract}

Kata Kunci: Peranan; Pencurian Kendaraan Bermotor; Reserse Kriminal; Polsek; Ubud

\begin{abstract}
The rise of crimes occurred in almost all over the world has appeared as the limelight not only for the security forces and the community but also for scholars or researchers to strive for uncovering the motives beyond the criminal acts and the strategies for prevention and settlement. As is the case in Indonesia, especially in the Bali territory - the main center of Indonesian tourism activities - crimes in various forms have often taken place. This study reveals the police efforts in uncovering the criminal acts of motor vehicle theft occurred at Jalan Andong, Desa Petulu, Ubud - Bali, as well as the inhibiting factors encountered. To achieve these goals, the study makes use of qualitative research design and empirical and sociological legal research methods. The results showed that there were two actions the police had taken. First, pre-emptive action was realised through community guidance through Non-Commissioned Officer (NCO) for People's Security and Order (most commonly known as BHABINKAMTIBMAS in Indonesia). The second is preventive action through patrol activities and control of the completeness of motorised vehicles. The latter is a repressive measure, in which the police took actions according to the police report models $(A)$ and $(B)$. In an effort to disclose this action, several obstacles were encountered, including: internal factors appearing in the form of inadequate number of investigators, facilities and equipment such as fingerprint scanners which were also inadequate and a limited budget; and external factors which include inadequate CCTV, the minimum number of witnesses, negligence of vehicle owners, perpetrators and stolen property had been outside Bali. The lack of witnesses, especially but not limited to recidivists, in an effort to expose the crime implies that sophisticated and adequate facilities and
\end{abstract}


equipment have the crucial functions, benefits, and urgency to be equipped in order to realise national security and peace. Related to this, Criminal Investigation Agency holds a crucial role that needs to be realised immediately.

Keywords: Role; Motor Vehicle Theft; Criminal Investigation Agency; Resort Police; Ubud

\section{PENDAHULUAN}

Indonesia merupakan salah satu negara dengan peningkatan pertumbuhan penduduk yang semakin hari semakin naik, sehingga mempengaruhi kondisi sosial ekonomi masyarakat. Kondisi ini, mudah menimbulkan masalah di bidang keamanan dan ketenangan, seperti terjadinya tindak pidana atau kejahatan yang dilakukan demi memenuhi kebutuhan kehidupanya. Minimnya lapangan pekerjaan memicu banyak oknum pelaku kejahatan demi kepenting kehidupanya (Britt, 1997; Cantor \& Land, 2001; Paternoster \& Bushway, 2001; Hojman, 2002; Edmark, 2005; Raphael \& Winter-Ebmer, 2005). Sebagai makhluk sosial manusia tidak dapat hidup sendiri melainkan saling membutuhkan antara satu dengan yang lainnya untuk menujang keberlangsungan kehidupanya.

Kendatipun demikian, manusia juga harus memiliki kemandirian diri. Di zaman modern, seperti saat ini, seseorang dituntut harus memiliki pendidikan yang tinggi disertai keterampilan sebagai modal mendapatkan pekerjaan yang layak baginya. Kejahatan merupakan perbuatan menyimpang yang memiliki nilai yang sangat tercela, sehingga perbuatan tersebut menimbulkan reaksi di lingkungan sosial masyarakat. Peran pemerintah dan penegak hukum dalam memberantas dan menanggulangi masih sering berakhir dengan kegagalan. Dengan demikan peran kepolisian sangat diperlukan dalam menangulangi semua jenis tindak kejahatan (Purnomo, 2014; Hartanto, 2015; dkk., 2017). Indonesia dikenal sebagai Negara yang melindungi dan menjamin keamanan serta kesejahteraan bagi rakyatnya. Di sinilah fungsi polisi terlihat.

Sebenarya, di dalam Undang-Undang No 2 Tahun 2002 tentang Kepolisian telah dicantumkan tugas dan wewenang kepolisian yaitu melayani dan mengayomi masyarakat. Sayangnya, perkembangan zaman yang semakin hari semakin meningkat ditandai dengan perkembangan di bidang teknologi yang semakin canggih mengakibatkan pelaku tindak kejahatan lebih pintar dalam merealisasikan kejahatanya. Salah satu bentuk kejahatan yang paling meresahkan masyarakat yaitu pencurian kendaraan bermotor. Bentuk kejahatan semacam ini memuat masyarakat menjadi tempat pelampiasan dan korban pencurian bermotor. Sebab cara atau teknik yang juga semakin canggih yang dipergunakan oleh para pelaku pencurian motor yang sulit didekteksi oleh aparat kepolisian (Azmi, 2014). Salah satunya ialah mengubah warna kendara dan mengubah identitas kendaraan itu sehingga terlihat seolah-olah bukanlah sebuah barang hasil curian atau tindak kejahatan. Di dalam kasus seperti ini peranan penyidik sangatlah penting untuk mampu mengungkapnya supaya tindakan kejahatan serupa tidak terulang di kemudian hari.

Tindakan kejahatan pencurian kendaraan dalam bentuk sepeda motor dalam beberapa dekade telah menjadi sebuah tren dalam kehidupan keseharian masyarakat di berbagai daerah di Indonesia. Salah satu peristiwa kejahatan ini adalah yang terjadi di Jalan Raya Andong, Desa Petulu, Kecamatan Ubud, Bali. Polisi mengamankan pelaku pencurian motor pada hari Sabtu 23 November 2019. Penangkapan mereka berawal dari adanya dua laporan kepada pihak kepolisian. Yakni, pencurian di Art Shop Jelitop dan Art Shop Artha Kesuma (http://bali.tribunnews.com/2019/11/26/oprasi-pekat-polsek-ubud-ringkus-2-malingmotor-di-tampaksiring-amankan-miras). Dengan demikian peranan aparat kepolisian dalam menangani kasus semacam itu ialah menindaklanjuti dan serta berusaha untuk mengungkapnya hingga menyelesaikanny secara tuntas dengan memberikan sanksi sesuai dengan ketentuan peraturan perundangundangan yang berlaku. Karena apa? Masyarakat menaruh harapan yang sangat besar kepada kepolisian sebagai pihak dengan otoritas dari Negara yang menjamin keamanan masyarakat.

Kajian tentang kasus kejatahan pencurian kendaraan bermotor telah dimulai dari beberapa dekade (Spector, 1975; Britt, 1997; Copes, 1999; Walsh \& Taylor, 2007; Levy, 2014; Piza et al., 2017). Terdapat sikap controversial dalam menanggapi kemunculan kejahatan ini karena terdapat bentuk kejahatan ini yang dilakukan karena terpaksa demi memenuhi kebutuhan (Paternoster \& Bushway, 2001; Cantor \& Land, 2001). Namun beberapa memandangnya dari sudut pandang hukum yang memandangnya tetap sebagai perbuatan yang patut memiliki sanksi (Azmi, 2014; Pasaribu et al., 2017). Kendatipun demikian, kejahatan akan terus terjadi selama manusia berevolusi di dunia ini. Oleh karena itu kajian-kajian ilmiahpun harus 
terus dilakukan. Bukan karena sebuah kajian tidak mampu memprediksi wajah masa depan kejahatan ini agar pencegahan dapat dilakukan sedini mungkun tetapi karena kehidupan manusia dan makhluk lainnya berevolusi dan sering mengalami adanya peristiwa yang tidak pernah terduga.

Dari uraian di atas tersebut, kajian ini dilakukan untuk meneliti dan mengkaji tentang tindak pidana kejahatan pencurian bermotor, karena peranan dari Reserse Kriminal dalam mengungkap sebuah kasus tersebut sangat penting demi pelaksanaan penegakan hukum agar tercipta keamanan di lingkungan masyarakat. Kajian ini menyoroti upaya yang telah dilakukan poleh pihak keamanan melului kepolisian dalam mengungkap sebuah kasus pencuruian bermotor di Kecamatan Ubud, Bali, serta kendala-kendala yang dihadapi.

Berdasarkan peryataan di atas, pokok permasalahan dalam penelitian ini adalah seperti berikut: (1) Bagaimanakah tindakan kepolisian untuk mengungkap tindak pidana pencurian bermotor di wilayah hukum Polsek Ubud? (2) Bagaimanakah faktor penghambat dalam penanganan tindak pidana pencurian bermotor di wiyalah tersebut? Adapun maksud tujuan yang ingin di capai penulisan dalam penelitian yaitu untuk mengetahui tindakan Reserse Kriminal dalam mengungkap tindak pidana pencurian bermotor di wilayah hukum Polsek Ubud dan untuk mengetahui faktor penghambat dalam penanganan tindak pidana pencurian bermotor tersebut.

\section{METODE PENELITIAN}

Metode penelitian adalah cara melakukan sesuatu dengan menggunakan pikiran secara seksama untuk mencapai suatu tujuan dengan cara mencari, mencatat merumuskan, dan menganalisa, sampai menyusun laporan (Narbuko \& Achmadi, 2003). Tipe penelitian dan pendekatan masalah yang digunakan dalam penelitian ini ialah pendekatan hukum empiris dan pendekatan yuridis sosiologis, dengan cara memperoleh fakta-fakta dan data yang terjadi melalui wawancara atau interview. Lokasi penelitian ialah Kepolisian Sektor Ubud yang terletak di Jalan Raya Andong, Peliatan Ubud, Kecamatan Gianyar, Kabupaten Gianyar dengan maksud melakukan wawancara terhadap Reserse Kriminal Kepolisian Sektor Ubud. Penelitian dimulai dengan mencari informasi tentang tindakan kejahatan pencurian kendaraan bermotor. Menyusun rencana pelaksanaan penelitian, termasuk menentukan model, pendekatan, dan metode pelaksanaan. Kemudian menentukan metode pengumpulan dan analisis data. Kemudian memilih lokasi penelitian, partisipan, dan waktu pelaksanaan. Kemudian, penelitian dilaksanakan dengan mengunjungi Kantor Kepolisian Sektor Ubud untuk mengadakan wawancara terbuka. Setelah itu, analisis dilakukan terhadap data yang sudah terkumpul dan menyajikan hasilnya secara deskriptif. Terakhir ialah menarik simpulan menurut hasil yang ditemukan.

\section{HASIL PENELITIAN DAN PEMBAHASAN}

Tindakan Kepolisian untuk Mengungkap Kasus Tindak Pidana Pencurian Bermotor di Wilayah Hukum Polsek Ubud

Dalam melaksanakan tugas tentu saja pihak kepolisian dituntut untuk melakukan tindakan-tindakan agar tercipta lingkungan masyarakat yang aman dan tertib. Dengan demikan tindakan tersebut antara lain melakukan tindakan preventif dan represif (Purnomo, 2014). Secara umum tindakan preventif adalah tindakan pencegahan, penangkalan, pengendalian sebelum kejahatan terjadi (Arief, 2008; Bryant, 2012), sedangkan tindakan penanggulangan kejahatan lewat jalur penal lebih menitikberatkan pada sifat represif penindakan, pemberantasan, penumpasan sesudah kejahatan terjadi (Soedarto, 1986). Dalam melaksanakan tindakan tersebut polisi harus berlandasan hukum, seperti yang diatur dalam Undang-Undang Nomor 2 Tahun 2002 tentang Kepolisian. Di dalam undang-undang tersebut dijelaskan tugas dan kewenangan kepolisian dalam melaksanakan tugasnya.

Di dalam melaksanakan tugas pokok penegak hukum tentu saja polisi harus berpegang pada ketentuan perundang-undangan yang berkaitan dengan tugas pokok kepolisian, dalam hal ini berkaitan dengan peradilan pidana; sebagai contoh Kitab Undang-Undang Hukum Pidana (KUHP), Kitab UndangUndang Hukum Acara Pidana (KUHAP) dan undang-undang yang berkaitan dengan peradilan pidana. Tidak hanya itu, dalam melaksanakan tugas pokok dan kewenangannya, aparat kepolisian harus atau diwajibkan melaksanakannya berdasarkan Standar Operasional Prosedur (SOP) Kepolisian. SOP 
merupakan panduan pelaksanaan rambu-rambu dalam tugas aparat kepolisian yang menjelaskan asas-asas dan prinsip kepolisian dalam melaksankan tugas pokok dan wewenangnya karena mereka wajib memahami tata cara pelaksanaanya agar tidak terjadi kesalahan dalam mengambil tindakan.

Terkait tindakan pencurian kendaraan bermotor (roda dua) di wilayah Kecamatan Ubud tentu saja, aparat kepolisian harus melakukan tindakan-tindakan agar tercipta lingkungan masyarakat yang aman dan nyaman. Maka, dari itu, tindakan Kepolisian Sektor Ubud melakukan tindakan pre-emtif, preventif, dan tindakan represif, yaitu:

a. Tindakan Pre-emtif

Berbicara tentang penanganan kejahatan oleh aparat kepolisian melalui tindakan pre-emtif berarti berbicara tentang tindakan yang dilakukan dengan cara memberikan pembinaan terhadap masyarakat (Muly, 2008). Dengan demikan tujuannya adalah memberikan bimbingan kepada masyarakat agar masyarakat menghindari perbuatan yang melanggar atau berbentuk kejahatan. Berdasarkan hasil wawancara dengan informan Reskrim Polsek Ubud, tujuan dilaksanakannya tindakan pre-emtif adalah agar masyarakat lebih waspada terhadap kejahatan pencurian kendaraan bermotor selain dari himbauan pembinaan tersebut juga dimandatkan kepada BHABINKAMTIBNAS dengan tujuan agar lingkungan masyarakat yang aman terciptan.

b. Tindakan Preventif

Berbicara tentang kebijakan non-penal berarti berbicara tentang tindakan-tindakan pencegahan terhadap terjadinya kejahatan dan sasaran utamanya adalah terkait dengan faktor-faktor yang dapat memicu terjadinya kejahatan (Arief, 2008). Oleh karena, tujuan dari tindakan preventif ialah mencipatakan suasana yang kondusif dan menekan terjadinya tindak kejahatan. Berdasarkan hasil wawancara dengan Reskrim Polsek Ubud, berkaitan dengan tindakan preventif aparat kepolisian tersebut melaksanakan patroli-patroli melalui Unit Sabhara dan melakukan pemeriksaan dan penertiban kelengkapan kendaraan bermotor melalui Unit Satlantas dengan tujuan agar tercipta situasi lingkungan masyarakat aman dari gangguan tindak kejahatan dan terpenuhinya persyaratan dokumen kelengkapan kendaraan bermotor beserta terdukungnya pengungkapan tindak pidana.

c. Tindakan Represif

Tindakan represif lebih dititikberatkan terhadap orang yang melakukan tindak pidana yang mencakup penjatuhan hukuman pidana yang setimpal atas perbuatan yang dilakukan (Dirdjosisworo, 1976). Dengan demikain tindakan-tindakan tersebut antara meliputi melakuan penyelidikan dan penyidikan guna mengungkap dan melaksanakan penegakan hukum. Berdasarkan keterangan hasil wawancara dengan Reskrim Kepolisian Sektor Ubud, dalam mengimplementasikan tindakan represif aparat kepolisian melakukan penyelidikan dan penyelidikan sesuai dengan Laporan Polisi Model (A) yang diketahui oleh petugas kepolisian atau bisa disebut tertangkap tangan dan melaksanakan Laporan Polisi Model (B) yang disampaikan oleh saksi-saksi maupun korban dari tindakan kejahatan.

\section{Faktor Penghambat dalam Penanganan Kasus Tindak Pidana Pencurian Bermotor di Wilayah Hukum Polsek Ubud}

Meningkatnya kasus tindak pidana pencurian bermotor yang terjadi di wilayah hukum Polsek Ubud memang tidak dapat terelakkan sebagai akibat dari meningkatnya kemajuan $\mathrm{d}$ al a $\mathrm{m}$ pertumbuhan perekonomian masyarakat sekitar, sehingga mengakibatkan kecemburuan sosial di lingkungan masyarakat (Dyck, 2010). Sudah sangat jelas bahwa sepeda motor merupakan kebutuhan yang sangat diperlukan dan dibutuhkan manusia dalam melakukan segala aktivitasnya dalam kehidupan sehari- hari, baik dipergunakan dalam mengangkut orang maupun barang dan sebagai alat yang membantu mempermudah pelaksanaan kegiatan sehari-hari. Dengan terjadinya tindak kejahatan pencurian kendaraan bermotor, tentu saja masyarakat yang menjadi korban sangat dirugikan.

Sepeda motor adalah kendaraan beroda dua yang digerakkan oleh sebuah mesin. Letak kedua roda sebaris lurus dan pada kecepatan tinggi sepeda motor tetap berjalan stabil disebabkan oleh gaya giroskopik (Dyck, 2010). Pengunaan sepeda motor di Indonesia sangat populer karena harganya yang relatif murah, terjangkau untuk sebagian besar kalangan dan juga menggunakan bahan bakar serta biaya operasionalnya cukup hemat (http://id.wikipedia.org/wiki/sepedamotor). Dengan demikian manfaat sepeda motor sangat 
membantu kebutuhan masyarakat. Kemudian dari data yang dikumpulan untuk penelitian ini, ditemukan adanya kasus-kasus yang ditangani oleh pihak Kepolisian Sektor Ubud. Ditemukan, jumlah keseluruhan kasus pencurian kendaraan bermotor di Kecamatan Ubud dari bulan Januari 2017 sampai dengan bulan Desember 2019 ialah 27 kasus. Dari 27 kasus tersebut hanya $60 \%$ saja yang berhasil diungkap. Ini mengindikasikan bahwa tindakan pencurian sepeda motor yang terjadi di wilayah tersebut disebabkan oleh tingginya kebutuhan masyarakat setempat akan kendaraan tersebut, akibatnya niat untuk melakukan pencurian bagi pihak-pihak tertentu, termasuk warga yang sedang mengganggur, timbul untuk memanfaatkan keadaan tersebut (Suresh \& Tewksbury, 2013). Karena itu, padatnya jumlah penduduk dalam suatu daerah atau wilayah memicu tingginya tingkat kebutuhan akan berbagai hal, seperti kendaraan, dan memicu semakin tingginya angka berbagai jenis kejahatan, termasuk pencurian kendaraan bermotor.

Melakukan tindakan kejahatan sering sekali bukan karena direncakan tetapi dipengaruhi oleh adanya suatu celah dalam masyarakat berupa kesempatan dalam saat tertentu. Dengan kata lain terjadinya tindak kejahatan disebabkan oleh berbagai faktor. Tindakan kejahatan pencurian kendaran bermotor di wilayah hukum Kepolisian Sektor Ubud disebabkan oleh dua faktor, yaitu faktor internal dan faktor eksternal.

a. Faktor Internal

Dalam kenyataan diakui bahwa masih ada aparat penegak hukum yang kurang profesional sehingga penegakan keadilan dalam penanganan kasus kejahatan sering terlambat dan bahkan tidak ada kecermatan (Harahap, 2003). Dengan demikian yang mengakibatkan seorang penyidik kurang profesional ialah faktorfaktor seperti kurangnya tenaga penyidik, sarana dan prasarana, dan anggaran yang diperlukan sehingga menghambat upaya penanganan. Keterangan tersebut disampaikan melalui wawancara dengan Reskrim Kepolisian Sektor Ubud bahwa faktor penghambat dalam penanganan di Polsek Ubud berkaitan dengan faktor internal kepolisian yang meliputi jumlah personil kepolisian yang kurang memadai, yakni hanya berjumlah 15 unit yang dibagi ke dalam beberapa bagian tugas, kemudian kurangnya sarana dan prasarana seperti alat pemindai sidik jari karena Polsek Ubud belum memiliki alat tersebut sehingga membutuhkan bantuan dari Polres tetangga yakni dari Kabupaten Gianyar. Selain itu, anggaran di berbagai Kepolisian Sektor, terutama di Polsek Ubud, sangat minim sehingga menyulitkan Reskrim dalam melaksanakan penegakan hukum.

\section{b. Faktor Eksternal}

Kesadaran hukum masyarakat yang masih rendah dapat menjadi hambatan bagi proses penegakan hukum. Memang diakui bahwa hal tersebut semata-mata menggambarkan rendahnya kesadaran hukum masyarakat, karena masih ada faktor lain (Harahap, 2003). Dengan demikian peranan masyarakat dalam menencegah terjadinya kejahatan sangat penting karena mampu membantu memberantas dan mencegah sekaligus mendukung pengungkapan tindak pidana pencurian motor. Berdasarkan hasil wawancara dengan pihak Reskrim Polsek Ubud, kendala yang berwujud faktor eksternal yang menjadi penghambat bagi Reskrim Polsek Ubud ialah tidak adanya saksi yang melihat pada saat terjadinya peristiwa pencurian motor, masyarakat tidak melihat dengan jelas perisitiwa sehingga menyulitkan aparat kepolisian dalam menelaah untuk mengungkap kasus tersebut. Hal lain ialah terdapat kelalaian pemilik kendaraan saat memarkir berupa kelupaan untuk menarik kembali kunci sepeda motor. Kemudian informasi terputus karna pelaku lihai dalam merencanakan kejahatannya sehingga pihak kepolisian terutama Reskrim sulit untuk mengungkap kasus tersebut serta pelaku dan barang bukti sudah berada di luar wilayah Bali.

\section{SIMPULAN DAN SARAN}

\section{Simpulan}

Penelitian mengkaji tentang upaya pihak kepolisian untuk mengungkap tindak kejatahan pencurian kendaraan bermotor di wilaya Polsek Ubud serta mengkaji kendala atau faktor-faktor penghamat yang ditemukan. Berdasar pada hasil dan pembahasan, simpulan analisis ini sebagai berikut. Pertama, tindakantindakan yang dilakukan oleh aparat kepolisian darui Polsek Ubud untuk mengungkap kasus tindakan pencurian kendaraan bermotor di wilayah tersebut ialah rtidan pre-emtif, tindakan preventif. Kedua, faktorfaktor penghambat upaya aparat kepolisian dalam mengungkap tindakan kejahatan tersebut terdiri dari faktor internal dan faktor eksternal. Faktor eksternal meliputi jumlah personil kepolisian yang belum 
memadai, sarana dan prasana yang belum memadai, dan sedikitnya jumlah anggaran yang dimiliki sehingga tidak memadai untuk melakukan pengungkapan kasus tersebut.

\section{Saran}

Didasari oleh hasil penelitian dan simpulan, kajian ini memberi beberapa rekomendasi terkait dengan objek kajiannya. Penerapan sanksi yang tegas bagi pelaku pencurian kendaraan bermotor terutama residivis dinilai sangat perlu mengingat masyarakat sebagai korban tindak kejahatan sangat dirugikan baik dari segi keyamanan, keselamatan, dan produktivitas mereka yang terganggu. Di sinilah peran penegak hukum terletak, baik yang bertugas merancang undang-undang maupun yang tugas melaksanakannya. Di samping itu, permasalahan yang sering timbul di Polsek-Polsek adalah mengenai kurangnya sarana dan prasarana beserta jumlah penyidik terutama di Reskrim yang mengakibatkan produktivitas dari penyidik tersebut menjadi terhambat. Perlu adanya perhatian khusus pemerintah dalam menambah tenaga penegak keadilan melalui Polsek.

Selain itu, sosialisasi mengenai mencegah dan mengantisipasi tindak kejahatan pencurian motor perlu diselenggarakan secara berkala dan berkesinambungan baik di sekolah-sekolah maupun di setiap banjarbanjar yang berada di wilayah Kecamatan Ubud guna menumbuhkan dan meningkatkan kewaspadaan dan pengamanan setiap pemilik atau pengguna kendaraan bermotor. Sebagai contoh, dengan mensosialisasikan tindakan atau cara memarkir kendaraannya di tempat yang bebas dari rawan tindak pidana pencurian motor dan memastikan bahwa kendaraan dalam keadaan terkunci pada saat terparkir, dan lebih waspada terhadap orang yang baru dikenal dan beserta masyarakat lebih aktif jika ada orang yang dicurigai agar segera melakukan pengaduan kepada pihak polisi.

\section{DAFTAR PUSTAKA}

Arief, B. N. (2008). Bunga Rampai Kebijakan Hukum Pidana (Perkembangan Penyusunan Konsep KUHP Baru). Kencana.

Azmi, N. A. (2014). Modus Operandi Kejahatan Pencurian Kendaraan Bermotor Roda Dua (Studi di Polresta Malang) (Vol. 53, Issue 9) [Kementerian Pendidikan dan KeudayaanUniversitas rawijaya]. https://doi.org/10.1017/CBO9781107415324.004

Britt, C. L. (1997). Reconsidering the unemployment and crime relationship: Variation by age group and historical period. Journal of Quantitative Criminology, 13(4), 405-428. https://doi.org/10.1007/BF02221048

Bryant, C. D. (2012). Routledge handbook of Deviant behavior. Routledge Handbook of Deviant Behavior, 1-618. https://doi.org/10.4324/9780203880548

Cantor, D., \& Land, K. C. (2001). Unemployment and Crime Rate Fluctuations: A Comment on Greenberg. Journal of Quantitative Criminology, 17(4), 329-342. https://doi.org/10.1023/A:1012585603639

Copes, H. (1999). Routine activities and motor vehicle theft: A crime specific approach. Journal of Crime and Justice, 22(2), 125-146. https://doi.org/10.1080/0735648X.1999.9721097

Dirdjosisworo, S. (1976). Penangulangan Kejahatan (Crime Prevention). Alumni.

Dyck, N. (2010). Social Class, Competition, and Parental Jealousy in Children's Sports. Blackwell Publishing Ltd, 498-515. https://doi.org/10.1002/9781444323542.ch21

Edmark, K. (2005). Unemployment and crime: Is there a connection? Scandinavian Journal of Economics, 107(2), 353-373. https://doi.org/10.1111/j.1467-9442.2005.00412.x

Harahap, C. (2003). Merajut Kolektivitas Melalui Penegakan Supremasi Hukum. Cita Pustaka Media.

Hartanto, E. (2015). Kebijakan Kriminal terhadap Pencegahan Pencurian Kenderaan Bermotor (Studi di Kepolisian Sektor Sunggal). USU Law Journal, 3(1), 1689-1699. https://doi.org/10.1017/CBO9781107415324.004

Hojman, D. E. (2002). Explaining Crime in Buenos Aires: The Roles of Inequality, Unemployment, and Structural Change. Bulletin of Latin American Research, 21(1), 121-128. https://doi.org/10.1111/1470-9856.00035

Levy, M. P. (2014). Motor Vehicle Theft. Encyclopedia of Criminology and Criminal Justice, 3167-3176. https://doi.org/10.1007/978-1-4614-5690-2_11 
Muly, M. (2008). Criminal Policy: Kebijakan Intregral Penangulangan Kejahatan Kekerasan. Pustaka Bangsa Press.

Narbuko, C., \& Achmadi, A. (2003). Metodologi Penelitian. P.T. Bumi Aksara.

Pasaribu, N., Ablisar, M., Mulyadi, M., \& Ikhsan, E. (2017). Penyidikan Kasus Tindak Pidana Pencurian dengan Pemberatan di Wilayah Hukum Polsek Medan Baru. USU Law Journal, 5(1), 1689-1699. https://doi.org/10.1017/CBO9781107415324.004

Paternoster, R., \& Bushway, S. D. (2001). Theoretical and Empirical Work on the Relationship between Unemployment and Crime. Journal of Quantitative Criminology, 17(4), 391-407. https://doi.org/10.1023/A:1012593805457

Piza, E., Feng, S., Kennedy, L., \& Caplan, J. (2017). Place-based correlates of Motor Vehicle Theft and Recovery: Measuring spatial influence across neighbourhood context. Urban Studies, 54(13), 29983021. https://doi.org/10.1177/0042098016664299

Purnomo, S. (2014). Upaya Kepolisian terhadap Penanggulangan Tindak Pidana Pencurian Kendaraan Bermotor (Studi Kasus di Polsek anjar Agung Kabupaten Tulang Bawang) [Universitas Bandar Lampung]. https://doi.org/10.1017/CBO9781107415324.004

Raphael, S., \& Winter-Ebmer, R. (2005). Identifying the Effect of Unemployment on Crime. SSRN Electronic Journal, November. https://doi.org/10.2139/ssrn.145790

Soedarto. (1986). Kapita Selekta Hukum Pidana. Alumni.

Spector, P. E. (1975). Population Density and Unemployment: The Effects on the Incidence of Violent Crime in the American City. Criminology, 12(4), 399-401. https://doi.org/10.1111/j.17459125.1975.tb00645.x

Suresh, G., \& Tewksbury, R. (2013). Locations of Motor Vehicle Theft and Recovery. American Journal of Criminal Justice, 38(2), 200-215. https://doi.org/10.1007/s12103-012-9161-7

Walsh, J. A., \& Taylor, R. B. (2007). Community structural predictors of spatially aggregated motor vehicle theft rates: Do they replicate? Journal of Criminal Justice, 35(3), 297-311. https://doi.org/10.1016/j.jcrimjus.2007.03.006 